\title{
Complications and risk factors related to the extent of surgery in thyroidectomy. Results from 2,043 procedures
}

\author{
Stauros N. Karamanakos ${ }^{1}$, Kostas B. Markou ${ }^{2}$, Konstantinos Panagopoulos ${ }^{1}$, \\ Dionisios Karavias ${ }^{1}$, Constantinos E. Vagianos ${ }^{1}$, Chrisoula D. Scopa ${ }^{3}$, \\ Vassiliki Fotopoulou ${ }^{2}$, Anna Liava ${ }^{3}$, Konstantinos Vagenas ${ }^{1}$ \\ ${ }^{1}$ Department of Surgery, ${ }^{2}$ Department of Internal Medicine, Division of Endocrinology, ${ }^{3}$ Department of Pathology, \\ University of Patras, Medical School, Patras, Greece
}

\begin{abstract}
OBJECTIVE: To evaluate the rate of complications and the risk factors in relation to the extent of surgery in patients undergoing thyroidectomy in a tertiary university center. DESIGN: Data were collected retrospectively from 2,043 consecutive patients who underwent thyroid surgery for various thyroid diseases at the University Hospital of Patras, Greece, between January 1996 and December 2007. Recurrent laryngeal nerve palsy (RLNP) and hypoparathyroidism were set as the primary end points, while hematoma and wound infection were set as the secondary endpoints. RESULTS: Total, near-total and subtotal thyroidectomy was performed in 1,149, 777 and 117 patients, respectively. Transient RLNP occurred in $34(1.6 \%)$ and permanent in $19(0.9 \%)$ patients. Multivariate logistic regression analysis showed that extended resection (OR-odds ratio-1.6), Graves' disease (OR 2.7), thyroiditis (OR 2.1), recurrent goiter (OR 2.3) and thyroid malignancy (OR 1.7) were all independent risk factors for transient RLNP, whereas Graves' disease (OR 2.2) and recurrent goiter (OR 1.7) emerged as independent risk factors for permanent RLNP. The rates of transient and permanent hypoparathyroidism were $27.8 \%$ and $4.8 \%$, respectively. Multivariate analysis for transient hypoparathyroidism revealed that the extent of surgical resection (OR 2.2), Graves' disease (OR 2.1), recurrent goiter (OR 1.7), female gender (OR 1.5) and specimen weight (OR 1.6) were independent predictors.-However, the extent of surgical resection (OR 2.7), Graves' disease (OR 1.8), recurrent goiter (OR 1.5) and malignant disease (OR 1.5) were independent risk factors for permanent hypoparathyroidism. Postoperative wound infection and hematoma occurred in $6(0.3 \%)$ and $27(1.3 \%)$ patients, respectively. No correlation was observed between wound infection or postoperative hemorrhage and the extent of surgery. CONCLUSIONS: Despite the higher morbidity, total thyroidectomy is emerging as an attractive surgical option even for benign thyroid disease due to the risk of subclinical (occult) malignancy, the possibility of goiter relapse as well as of the increased risk of complications following reoperation.
\end{abstract}

Keywords: Complications of thyroidectomy, Hypoparathyroidism, Recurrent laryngeal nerve palsy, Thyroidectomy 


\section{INTRODUCTION}

Disorders of the thyroid gland constitute the second most common endocrine disease following diabetes mellitus. ${ }^{1}$ The prevalence of nodular goiter and thyroid autonomy is increased in regions with chronic Iodine Deficiency (ID). ${ }^{2}$ It has been documented that the thyroid gland adjusts to ID in the early stages by diffuse hyperplasia, while chronic exposure to ID results in nodular hyperplasia, increased colloid content and increased height of the follicular cells. ${ }^{3}$

Thyroidectomy is one of the most frequent operations performed in iodine-deficient regions. ${ }^{4-6}$ In the early $20^{\text {th }}$ century, thyroidectomy was associated with increased morbidity and even mortality. ${ }^{7}$ However, today the improvements in anesthesia and antisepsis as well as better surgical instrumentation and improvement in the surgical technique have rendered thyroidectomy an efficacious and safe treatment modality with acceptable morbidity and even unrecorded mortality. ${ }^{8-10}$ Currently, the main postoperative complications of thyroidectomy are Recurrent Laryngeal Nerve Palsy (RLNP) and hypoparathyroidism.

The etiology of postoperative hypoparathyroidism has been proven to be multifactorial, with the surgical technique, the devascularization and accidental resection of the parathyroid glands being the most significant factors. ${ }^{11}$ It is also related to the type of thyroid pathology, with Graves' disease, ${ }^{12}$ recurrent goiter ${ }^{13}$ and thyroid carcinoma ${ }^{14}$ carrying the highest risk.

In Greece, Nontoxic Nodular Goiter (NTNG) was endemic 35 years ago because of iodine deficiency. ${ }^{15}$ Nowadays, most of Greece is an iodine-sufficient country with only a few small regions remaining iodine deficient. ${ }^{16}$ The aim of the present study was to evaluate the incidence and the risk factors for complications in patients undergoing thyroidectomy in a tertiary university center which serves the southwestern region of Greece.

\section{MATERIALS AND METHODS}

Between January 1996 and December 2007 a total of 2,043 consecutive patients underwent thyroid surgery for a variety of thyroid diseases at the University Hospital of Patras, Greece. Data were retrieved retrospectively from our surgery department data base. In accordance with our protocol, ${ }^{17,18}$ preoperative work-up included physical examination, thyroid function tests, cervical ultrasonography and/or thyroid scintigraphy and in selected cases Computed Tomography (CT) or Magnetic Resonance Imaging (MRI). Fine-Needle Aspiration Biopsy (FNAB) was performed for clinically palpable dominant thyroid nodules.

All operations were performed by staff surgeons specialized in endocrine surgery. Total thyroidectomy was carried out by extracapsular dissection. Neartotal thyroidectomy was performed by the capsular dissection method, leaving $<2 \mathrm{~g}$ of remnant tissue. In this paper, total and near-total thyroidectomies are referred to as extended thyroidectomy, whereas subtotal thyroidectomy is referred to as conservative thyroidectomy. Subtotal thyroidectomy was also carried out by the capsular dissection method, which leaves approximately 4-5 g of remnant tissue. Intraoperatively, efforts were made to identify and preserve the recurrent laryngeal nerves. Identification of at least two parathyroid glands was considered sufficient and meticulous dissection was adopted so as to preserve vascularization and the integrity of the gland. In one case of inadvertent parathyroid removal, the gland was autotransplanted into the neck muscles. Following completion of thyroidectomy, a drain was placed according to the surgeon's judgment and not routinely.

Vocal cords were assessed by the anesthesiologist during extubation and by an Ear-Nose-Throat (ENT) specialist in case of symptoms development. Permanent RLNP was defined as sustained immobility of the vocal cords six months after surgery. Routinely, serum calcium levels were assessed the day after the operation. Hypocalcemia was defined as serum calcium levels under $8.0 \mathrm{mg} / \mathrm{dl}$ and in all such cases oral calcium supplementation and $1(25 \mathrm{OH})$ Vit $\mathrm{D}$ was administered. Intravenous administration of calcium gluconate was preserved for patients with clinical symptoms and signs of hypocalcemia. Permanent hypoparathyroidism is defined as the requirement of calcium supplementation and/or vitamin D to maintain eucalcemia six months postoperatively.

All patients with postoperative complications 
attended our endocrine outpatient clinic at regular intervals and until 12 months after the operation. During follow-up visits complete patient evaluation was undertaken, including medications, physical examination and blood sampling for serum calcium levels. Patients who developed postoperative complication and could not attend the outpatient clinic were consulted by telephone.

Development of RLNP and hypoparathyroidism were set as primary endpoints. Hemorrhage and wound infection were the secondary endpoints. Patients' age and gender, surgeons' experience, thyroid pathology, extent of resection and specimen weight (extracted from the pathology files) were also assessed as risk factors for the development of the above complications.

\section{STATISTICAL ANALYSIS}

Changes in serum calcium levels during the hospital stay in the three groups of patients were compared using ANOVA and the Student's $t$-test was applied for repeated measures. The predictive factors for RLNP and hypoparathyroidism were evaluated by univariate analysis and multivariate logistic regression analysis. Results were considered statistically significant when $\mathrm{P}$-value was $<0.05$.

\section{RESULTS}

During the study period 2,043 thyroidectomies were performed. There were 346 men (16.9\%) and 1,697 women $(83.1 \%)$ with a mean \pm SD age of $48.5 \pm 13.6$ years. The mean \pm SD time of operation was $123.7 \pm 27.9$ minutes and the mean \pm SD time of hospitalization $2.2 \pm 1.6$ days. Preoperative diagnosis of benign or malignant disease was made in 1,961 (96\%) and $82(4 \%)$ patients, respectively. Patients' data on the indications for surgery, operative time and length of hospital stay, age and gender are listed in Table 1.

There were 1,149 total, 777 near-total and 117 subtotal thyroidectomies. The vast majority of STTs were performed in the early study period, while TTs predominated later on (Figure 1). The mean weight of the excised thyroid specimens was 44.9 gr. No significant differences were recorded among the three types of procedures concerning the operative times and the convalescence.

Transient and permanent RLNP occurred in 34 $(1.6 \%)$ and $19(0.9 \%)$ patients, respectively. Univariate analysis showed no significant correlation between

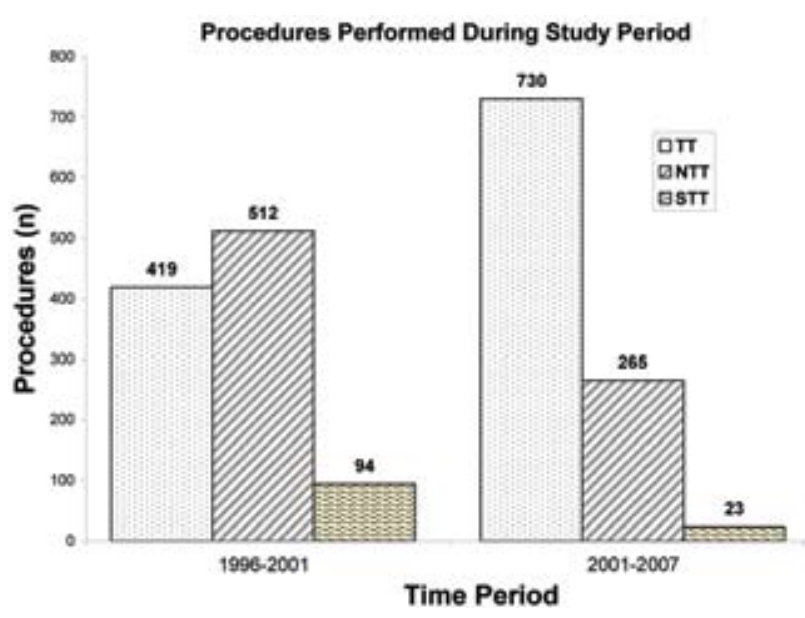

Figure 1. Procedures performed during the study period.

Table 1. Patients' demographic data and indications for surgery.

\begin{tabular}{lcccccc}
\hline Indications for Surgery & $\begin{array}{c}\text { Number of } \\
\text { patients (n) }\end{array}$ & $\begin{array}{c}\text { Males } \\
(\mathbf{n})\end{array}$ & $\begin{array}{c}\text { Females } \\
(\mathbf{n})\end{array}$ & $\begin{array}{c}\text { Mean Age } \\
\text { (Years) }\end{array}$ & $\begin{array}{c}\text { Mean Operative } \\
\text { Time (min) }\end{array}$ & $\begin{array}{c}\text { Mean Hosp. } \\
\text { Stay (days) }\end{array}$ \\
\hline Multinodular goiter & 1503 & 244 & 1259 & 48.7 & 117.7 & 1.7 \\
Uninodular goiter & 315 & 58 & 257 & 45.7 & 105.3 & 1.5 \\
Graves' disease & 63 & 13 & 50 & 43.2 & 143.2 & 3.1 \\
Thyroiditis* & 27 & 2 & 25 & 48.6 & 141.8 & 2.0 \\
Thyroid Carcinoma & 82 & 12 & 70 & 49.5 & 135.1 & 2.3 \\
Reoperations** & 53 & 17 & 36 & 49.2 & 151.3 & 3.1 \\
Total no. of Procedures & 2043 & 346 & 1697 & 48.5 & 123.7 & 2.2 \\
\hline
\end{tabular}

* Including Hashimoto's and De Quervain thyroiditis, ** For recurrent goiter and incidental papillary carcinoma 
the extent of thyroidectomy and RLNP (Table 2). The rates of transient and permanent hypoparathyroidism were $27.8 \%$ and $4.8 \%$, respectively. Univariate analysis revealed a significant correlation between the extent of thyroid resection and the development of postoperative hypoparathyroidism (Table 2$)(\mathrm{P}<0.001)$. Postoperative wound infection occurred in six patients $(0.3 \%)$ and was managed conservatively with wound debridement and antibiotics. Twenty-seven patients $(1.3 \%)$ developed postoperative hematoma, and nine patients were reoperated on because of compressive symptoms and ongoing hemorrhage. In all but one case, a drain was placed. No correlation was found between wound infection or postoperative hemorrhage and the extent of surgery (Table 2).

Though total thyroidectomy was our procedure of choice in the study period 2001-2007, there were no significant differences in morbidity in relation to the early period, in which less extensive procedures, were mainly performed with the exception of permanent RLNP which was observed at a higher rate in the early period $(\mathrm{P}=0.03)$, while wound infection was more common in the more recent period $(\mathrm{P}<0.001)$ (Table 3).

The results of multivariate analysis for transient and permanent RLNP are given in Table 4. Graves' disease (OR 2.7), thyroiditis (OR 2.1), recurrent goiter (OR 2.3), malignant disease (OR 1.7) and extended thyroid resection (OR 1.6) were all independent risk factors for transient RLNP. When multivariate analysis was confined to permanent RLNP, Graves' disease (OR 2.2) and recurrent goiter (OR 1.7) emerged as

Table 2. Distribution of complications among various thyroidectomy procedures.

\begin{tabular}{lccccc}
\hline Complications & Total $\mathbf{n}(\%)$ & TT n(\%) & NTT n(\%) & STT n(\%) & P* \\
\hline Transient RLNP & $34(1.6)$ & $22(1.9)$ & $10(1.3)$ & $2(1.1)$ & NS \\
Permanent RLNP & $19(0.9)$ & $12(1.1)$ & $6(0.7)$ & $1(0.85)$ & NS \\
Transient Hypoparathyroidism & $568(27.8)$ & $392(34.1)$ & $167(21.5)$ & $7(8.2)$ & $<0.001$ \\
Permanent Hypoparathyroidism & $98(4.8)$ & $72(6.3)$ & $25(3.2)$ & $1(0.85)$ & $<0.001$ \\
Wound Infection & $6(0.3)$ & $4(0.3)$ & $1(0.1)$ & $1(0.85)$ & NS \\
Hematoma & $27(1.3)$ & $14(1.2)$ & $11(1.4)$ & $2(1.7)$ & NS \\
\hline
\end{tabular}

RLNP: Recurrent Laryngeal Nerve Palsy, TT: Total Thyroidectomy, NTT: Near-Total Thyroidectomy, STT: Subtotal Thyroidectomy, NS: Non-Significant, P* among TT and NTT and STT.

Table 3. Procedures and complications in the early and more recent study period.

\begin{tabular}{|c|c|c|c|c|c|}
\hline & \multicolumn{4}{|c|}{ Study Period } & \multirow[b]{3}{*}{$\mathbf{P}$} \\
\hline & \multicolumn{2}{|c|}{ 1996-2001 } & \multicolumn{2}{|c|}{ 2001-2007 } & \\
\hline & $\mathbf{N}$ & $\%$ & $\mathbf{N}$ & $\%$ & \\
\hline Total procedures $(n=2043)$ & 1025 & 50.2 & 1018 & 49.8 & NS \\
\hline $\mathrm{TT}(\mathrm{n}=1149)$ & 419 & 36.5 & 730 & 63.5 & $<0.001$ \\
\hline NTT (n=777) & 512 & 65.9 & 265 & 34.1 & $<0.001$ \\
\hline $\operatorname{STT}(\mathrm{n}=117)$ & 94 & 80.3 & 23 & 19.7 & $<0.001$ \\
\hline Transient RLNP $(n=34)$ & 19 & 55.9 & 15 & 44.1 & NS \\
\hline Permanent RLNP (n=19) & 11 & 57.9 & 8 & 42.1 & 0.03 \\
\hline Transient Hypoparathyroidism $(\mathrm{n}=568)$ & 274 & 48.2 & 294 & 51.8 & NS \\
\hline Permanent Hypoparathyroidism $(n=98)$ & 47 & 47.9 & 51 & 52.1 & NS \\
\hline Wound Infection $(n=6)$ & 2 & 33.3 & 4 & 66.7 & $<0.001$ \\
\hline Hematoma $(n=27)$ & 15 & 55.5 & 12 & 44.5 & NS \\
\hline
\end{tabular}

NS: Non-Significant 
Table 4. Multivariate Logistic regression analysis for transient and permanent recurrent laryngeal nerve palsy (RLNP).

\begin{tabular}{lcccccc}
\hline & \multicolumn{2}{c}{$\begin{array}{c}\text { Transient } \\
\text { RLNP }\end{array}$} & & \multicolumn{2}{c}{$\begin{array}{c}\text { Permanent } \\
\text { RLNP }\end{array}$} \\
\cline { 2 - 3 } \cline { 6 - 7 } Parameters & OR & P & & OR & P \\
\hline Age & 0.9 & 0.54 & & 1 & 0.84 \\
Gender & 1.2 & 0.48 & & 1.1 & 0.67 \\
Extent of Resection* & 1.6 & 0.03 & & 1.3 & 0.12 \\
Graves' Disease & 2.7 & $<0.001$ & & 2.2 & $<0.001$ \\
Recurrent Goiter & 2.3 & $<0.001$ & & 1.7 & 0.03 \\
Thyroid Carcinoma & 1.7 & 0.01 & & 1.4 & 0.09 \\
Thyroiditis & 2.1 & $<0.001$ & & 1.5 & 0.06 \\
Specimen Weight $(>45 \mathrm{~g})$ & 1.2 & 0.32 & & 1.1 & 0.7 \\
\hline
\end{tabular}

* Total versus subtotal and versus near total thyroidectomy

independent risk factors. In contrast, gender, age and specimen weight above 45 grams were not found to play a role in transient or permanent RLNP (Table 4).

On multivariate analysis for transient hypoparathyroidism, the extent of surgical resection (OR 2.2), Graves' disease (OR 2.1), recurrent goiter (OR 1.7), female gender (OR 1.5) and specimen weight above 45 grams (OR 1.6) constituted independent risk factors (Table 5). When multivariate analysis was confined to permanent hypoparathyroidism, the extent of surgical resection (OR 2.7), Graves' disease (OR

Table 5. Multivariate Logistic regression analysis for transient and permanent hypoparathyroidism.

\begin{tabular}{|c|c|c|c|c|}
\hline \multirow[b]{2}{*}{ Parameters } & \multicolumn{2}{|c|}{$\begin{array}{l}\text { Transient } \\
\text { Hypoparathy- } \\
\text { roidism }\end{array}$} & \multicolumn{2}{|c|}{$\begin{array}{l}\text { Permanent } \\
\text { Hypoparathy- } \\
\text { roidism }\end{array}$} \\
\hline & OR & $\mathbf{P}$ & OR & $\mathbf{P}$ \\
\hline Age & 1.1 & 0.65 & 1.1 & 0.65 \\
\hline Gender & 1.5 & 0.05 & 1.2 & 0.34 \\
\hline Extent of Resection* & 2.2 & $<0.001$ & 2.7 & $<0.001$ \\
\hline Graves' Disease & 2.1 & $<0.001$ & 1.8 & 0.003 \\
\hline Recurrent Goiter & 1.7 & 0.006 & 1.5 & 0.01 \\
\hline Thyroid Carcinoma & 1.4 & 0.11 & 1.5 & 0.008 \\
\hline Thyroiditis & 1.3 & 0.32 & 1.4 & 0.09 \\
\hline Specimen Weight $(>45 \mathrm{~g})$ & 1.6 & 0.02 & 1.3 & 0.07 \\
\hline
\end{tabular}

* Total versus subtotal and versus near total thyroidectomy
1.8), recurrent goiter (OR 1.5) and malignant disease (OR 1.5) emerged as significant predictors. Age was not an independent risk factor either for permanent or for transient hypoparathyroidism.

In 52 of the thyroid specimens in which no neoplasia had been suspected $(2.65 \%)$, histologic examination revealed the presence of microcarcinoma (occult). Eleven of these cases had initially been managed with STT and were reoperated on. The remaining belonged to the TT group. Recurrent goiter was documented in 55 cases $(6.1 \%$ ) (31 in the STT group and 24 in the NTT group). Thirteen patients refused further surgical intervention and were managed with suppression therapy, while 42 were subjected to total thyroidectomy.

\section{DISCUSSION}

In this study it is clearly demonstrated that patients who underwent thyroidectomy for various reasons, in an area with prior history of ID followed by iodine sufficiency, did not have higher risk of surgical complications than those chronically living in iodine replete regions. ${ }^{7,14}$

Greece was an iodine-deficient area throughout the 20th century. Recent reports have shown, that the situation has been improved with an increase in iodine intake due to improved socioeconomic conditions and to the use of iodine enriched salt. However, a few isolated areas with mild ID still exist. ${ }^{16}$ Southwestern Greece is inhabited by approximately two million people. The region includes rural mountainous areas, seaside towns and villages as well as some big urban areas. The patients in the present study were residents of southwestern Greece and were over 20 years of age. Thus, they have been exposed to an iodine-deficient environment, at least early in their life, and for this reason the majority of them harboured multinodular goiters. Thyroidectomy is one of the most frequent operations performed in iodine-deficient regions and, though currently southwestern Greece is in a transition period from ID to an iodine sufficiency state, thyroidectomy is one of the most common procedures performed in our institution.

Thyroidectomy, one of the main forms of treatment for thyroid gland diseases, is performed worldwide by 
surgeons with varied background and expertise. The indications for surgery in these cases were suspicion of cancer, a massive goiter with symptoms of local compression, nodules with low radioiodine uptake (cold nodules) and patients' desire for rapid and definitive treatment. ${ }^{17-24}$ The extent of thyroidectomy in the management of thyroid diseases is a disputed issue among researches and there is still no consensus as to how much thyroid tissue should be left behind. ${ }^{24}$ Subtotal thyroidectomy has been the gold standard for patients with benign thyroid diseases. The proponents of this technique suggest that leaving a small remnant of functional gland results in euthyroidism without the need for replacement therapy and is associated with a lower risk of damaging the recurrent laryngeal nerves and the parathyroid glands. ${ }^{26,27}$ Nevertheless, the above approach has recently been challenged by endocrine surgeons who support total thyroidectomy and have demonstrated better control of thyroid disease and even comparable morbidity to subtotal thyroidectomy. ${ }^{28-31}$ Due to these encouraging reports, total thyroidectomy has gained acceptance among the surgeons of our institution and over the last few years it has rapidly displaced the more conservative surgical approaches.

Recurrent laryngeal nerve palsy is the most serious complication in thyroid surgery ${ }^{32}$ resulting in significant impairment of the quality of life $^{33}$ and having a negative impact on job performance. ${ }^{34}$ The incidence of RLNP varies from $0 \%$ to $4 \%$ and has been related to the extent of thyroidectomy, the presence of Graves' disease, thyroid carcinoma and the need for reoperation. ${ }^{35,36}$ In the present study, transient RLNP occurred in $1.6 \%$ cases and permanent RLNP in $0.9 \%$. In a recent multicenter trial of 16,448 thyroidectomies, Dralle $\mathrm{H}$. et $\mathrm{al}^{37}$ concluded that routine visual nerve identification and preservation should be the gold standard in thyroid surgery. In our institution, intra-operative nerve identification is the standard practice and thus it was not analyzed as an independent risk factor. Extensive resections, preoperative diagnosis of thyroid malignancy and recurrent goiter were identified as significant independent risk factors for RLNP in a recent study by Thomusch et al. ${ }^{38}$ In agreement with the above study, extensive resection (OR 1.6), recurrent goiter (OR 2.3) and the presence of thyroid carcinoma (OR 1.7) were among the major risk factors in our material for transient RLNP. Other significant risk factors for transient RLNP included Graves' disease (OR 2.7) and thyroiditis (OR 2.1). For permanent RLNP, Graves' disease (OR 2.2) and recurrent goiter (OR 1.7) were the most frequent risks. Though extensive resection has been shown to be a significant risk factor for permanent RLNP, ${ }^{36-38}$ in our study permanent RLNP was not related to TT.

Postoperative hypoparathyroidism is a major concern leading to prolonged hospitalization and increased cost. In several studies, the incidence of transient hypocalcemia varied from $6.9 \%{ }^{39}$ to $46 \%,{ }^{40,41}$ while a rate of $0.4 \%$ to $33 \%$ has been reported for permanent hypoparathyroidism. ${ }^{14,39}$ In the present study, transient hypoparathyroidism occurred in $27.8 \%$ of cases -568 patients - and it was mostly manifested as transient hypocalcemia, which was easily managed with oral supplementation of vitamin $\mathrm{D}$ and $\mathrm{Ca}^{+3}$. Clinical signs of hypocalcemia requiring intravenous administration of calcium gluconate were encountered in 94 patients (4.6\%). Finally, the corresponding rate for permanent hypoparathyroidism was $4.8 \%$. Recent studies have shown that the risk of postoperative hypoparathyroidism is related to the extent of thyroid resection. ${ }^{13,38,42}$ In full agreement with the aforementioned studies, following extensive resection the relative risks for transient and permanent hypoparathyroidism detected in the present study were 2.2 and 2.7, respectively. The multivariate analysis revealed that Graves' disease, recurrent goiter, specimen weight and female gender were potential risk factors for transient hypoparathyroidism. The extensive adhesions between the thyroid capsule and the parathyroid gland in Graves' disease and after reoperation as well as the more delicate anatomy in women most likely account for an increased risk of parathyroid injury during dissection.

Hematoma following thyroid surgery is a rare event occuring in $<1 \%$ to $2 \%$ of all thyroidectomies. ${ }^{43}$ Nevertheless, it can be a significant burden leading to airway obstruction, which is a surgical emergency. In our study hematoma was a complication in 27 cases $(1.3 \%)$ and reoperation was undertaken in nine due to ongoing hemorrhage and airway obstruction. Univariate analysis revealed no association between hematoma and the extent of resection. 
At the beginning of the $20^{\text {th }}$ century postoperative infection was a major complication of thyroidectomy. ${ }^{7,44}$ Nowadays, with the benefit of antisepsis and the constant progress of surgical techniques, the overall risk of postoperative wound infection is substantially decreased. In our series it occurred in six cases (0.3\%) all of which were successfully managed with wound debridement and antibiotics. We did not find any association between wound infection and extent of thyroid resection.

In conclusion, in the present study, total thyroidectomy confers certain advantages over less offensive procedures, but it is associated with higher morbidity. Nevertheless, due to the risk of an unsuspected malignancy and the possibility of goiter relapse following conservative surgery, as well as the increased risk of complications following reoperation, total thyroidectomy is emerging as an attractive surgical option.

\section{GRANTS OR FELLOWSHIP SUPPORTS}

The authors of the current manuscript declare that there are no commercial associations or whatsoever that might create a conflict of interest in connection with submitted manuscripts.

\section{REFERENCES}

1. Tunbridge WM, Evered DC, Hall R, et al, 1977 The spectrum of thyroid disease in a community: the Wickham survey. Clin Endocrinol (Oxf) 7: 481-493.

2. Laurberg P, Nohr SB, Pedersen KM, et al, 2000 Thyroid disorders in mild iodine deficiency. Thyroid 10: 951963.

3. Studer H, Derwahl M, 1995 Mechanisms of nonneoplastic endocrine hyperplasia - a changing concept: a review focused on the thyroid gland. Endocr Rev 16:411-426.

4. Bellantone R, Lombardi CP, Bossola M, et al, 2002 Total thyroidectomy for management of benign thyroid disease: review of 526 cases. World J Surg 26: 14681471.

5. Bron LP, O’Brien CJ, 2004 Total thyroidectomy for clinically benign disease of thyroid gland. Br J Surg 91: 569-574.

6. Acun Z, Comert M, Cihan A, Ulukent SC, Ucan B, Cakmak GK, 2004 Near-total thyroidectomy could be the best treatment for thyroid disease in endemic regions. Arch Surg 139: 444-447.

7. Moulton-Barrett R, Crumley R, Jalilie S, et al, 1997 Complications of thyroid surgery. Int Surg 82: 63-66.
8. Kocher T, 1874 Zur Pathologie und Therapie des Kropfes. Dtsch Z Chir 4: 417.

9. Halsted WS, 1920 The operative story of goiter: the author's operation. Johns Hopkins Rep 19: 71.

10. De Quervain F, 1912 Zur Technik der Kropfoperation. Dtsch Z Chir 116: 574.

11. Reeve T, Thompson NW, 2000 Complications of Thyroid Surgery: How to Avoid Them, How to Manage Them, and Observations on Their Possible Effect on the Whole Patient. World J Surg. 24: 971-975.

12. Michie W, Duncan T, Hamer-Hodges DW, 1971 Mechanisms of hypocalcemia after thyroidectomy for thyrotoxicosis. Lancet 1: 508-514.

13. McHenry CR, Speroff T, Wintworth D, Murphy T, 1994 Risk factors for postthyroidectomy hypocalcemia. Surgery 116: 641-648.

14. Wingert DO, Friesen SR, Iliopoulos GI, Pierce GE, Thomas JH, Hermreck AS, 1986 Post-thyroidectomy hypocalcemia. Incidence and risk factors. Am J Surg 152: 606-609.

15. Malamos B, Koutras DA, Kostamis P, Kralios AC, Rigopoulos G, Zerefos N, 1966 Endemic goiter in Greece: epidemiologic and genetic studies. J Clin Endocrinol Metab 26: 688-695.

16. Michalaki M, Kyriazopoulou V, Paraskevopoulou P, Vagenakis AG, Markou KB, 2008 The Odyssey of Nontoxic Nodular Goiter (NTNG) in Greece under Suppression Therapy, and after Improvement of Iodine Deficiency. Thyroid 18: 641-645.

17. Spiliotis J, Scopa CD, Gatopoulou C, Chalmoukis A, Androulakis J, Vagenakis A, 1991 Diagnosis of thyroid cancer in southwestern Greece. Bull Cancer 78: 953959.

18. Kakkos SK, Scopa CD, Chalmoukis AK, et al, 2000 Relative risk of cancer in sonographically detected thyroid nodules with calcifications. J Clin Ultrasound 28: 347-352.

19. Prades JM, Dumollard JM, Timoshenko A, et al, 2002 Multinodular goiter: surgical management and histopathological findings. Eur Arch Otorhinolaryngol 259: 217-221.

20. Okamoto T, Iihara M, Obara T, 2000 Management of hyperthyroidism due to Graves' and nodular diseases. World J Surg 24: 957-961.

21. Hurley DL, Gharib H, 1996 Evaluation and management of multinodular Goiter. Otolaryngon Clin North Am 29: 527-540.

22. Day TA, Chu A, Hoang KG 2003 Multinodular goiter. Otolaryngon Clin North Am 36: 35-54.

23. Erickson D, Gharib H, Li H, van Heerden JA, 1998 Treatment of patients with toxic multinodular goiter. Thyroid 8: 277-282.

24. Melliere D, Etienne G, Becquemin JP, 1988 Operation for hyperthyroidism: Methods and rationale. Am J Surg 155: 395-399.

25. Ku CF, Lo CY, Chan WF, Kung AWC, Lam KSL, 2005 
Total thyroidectomy replaces subtotal thyroidectomy as the preferred surgical treatment for Graves' disease. ANZ J Surg 75: 528-531.

26. Wagner HE, Seiler C, 1994 Recurrent laryngeal nerve palsy after thyroid gland surgery. Br J Surg 81: 226228.

27. Lasagna B, Resegotti A, De Paolis P, Balbo G, 1993 Extension of thyroidectomy in the treatment of benign nodular thyroid diseases. Minerva Chir 48: 14211424.

28. Razack MC, Lore JM, Lippes HA, Schaefer PD, Rassael H, 1997 Total thyroidectomy for Graves' disease. Head Neck 19: 378-383.

29. Miccoli P, Vitti P, Rago T, et al, 1996 Surgical treatment of Graves' disease: subtotal or total thyroidectomy? Surgery 120: 1020-1025.

30. Hermann M, Roka R, Richter B, Freissmuth M, 1998 Early relapse after operation for Graves' disease. Postoperative hormone kinetics and outcome after subtotal, near-total and total thyroidectomy. Surgery 124: 894900 .

31. Barakate MC, Agarwal G, Reeve TS, Ballaclough B, Bobinson B, Delbridge L, 2002 Total thyroidectomy is now the preferred option for the surgical management of Graves' disease. ANZ J Surg 72: 321-324.

32. Steurer M, Passler C, Denk DM, Schneider B, Niederle B, Bigenzahn W, 2002 Advantage of recurrent laryngeal nerve identification in thyroidectomy and parathyroidectomy and the importance of preoperative and postoperative laryngoscopic examination in more than 1000 nerves at risk. Larnygoscope 112: 124-133.

33. Smith E, Verdolini K, Gray S, Nichols S, Lemke J, Barkmeier J, 1996 Effect of voice disorders on quality of life. J Med Speech-Language Pathol 4: 223-244.

34. Smith E, Taylor M, Mendoza M, Barkmeier J, Lemke J, Hoffman H, 1998 Spasmodic dysphonia and vocal fold paralysis: outcomes of voice problems on work-related functioning. J Voice 12: 223-232.

35. Diderick BW, de Roy van Zuidewijn DB, Songun I, Kievit J, van de Velde CJ, 1995 Complications of thyroid surgery. Ann Surg Oncol 2: 56-60.

36. Erbil Y, Barbaros U, Işsever H, et al, 2007 Predictive factors for recurrent laryngeal nerve palsy and hypoparathyroidism after thyroid surgery. Clin Otolaryngol 32: 32-37.

37. Dralle H, Sekulla C, Haerting J, et al, 2004 Risk factors of paralysis and functional outcome after recurrent laryngeal nerve monitoring in thyroid surgery. Surgery 136:1310-1322.

38. Thomusch O, Machens A, Sekulla C, et al, 2000 Multivariate analysis of risk factors for postoperative complications in benign goiter surgery: prospective multicenter study in Germany. World J Surg 24: 1335-1341.

39. Falk SA, Birken EA, Baran DT, 1998 Temporary postthyroidectomy hypocalcemia. Arch Otolaryngol Head Neck Surg 114:168-174.

40. Percival RC, Hargreaves AW, Kanis JA, 1985 The mechanism of hypocalcemia following thyroidectomy. Acta Endocrinol 109: 220-226.

41. See ACH, Soo KC, 1997 Hypocalcemia following thyroidectomy for thyrotoxicosis. Br J Surg 84: 95-97.

42. Thomusch O, Machens A, Sekulla C, Ukkat J, Brauckhoff M, Dralle H, 2003 The impact of surgical technique on postoperative hypoparathyroidism in bilateral thyroid surgery: a multivariate analysis of 5846 consecutive patients. Surgery 133: 180-185.

43. Sippel RS, Chen H, 2006 Reoperative endocrine surgery. In: Caller $\mathrm{M}$ editor. Handbook of reoperative general surgery. Maiden, Mass: Blackwell: 135-150.

44. Pezzulo L, Delrio P, Losito NS, Caracò C, Mozzillo N, 1997 Post-operative complications after completion thyroidectomy for differentiated thyroid cancer. Eur J Surg Oncol 123: 215-218. 